Tropical Journal of Pharmaceutical Research February 2018; 17 (2): 293-298

ISSN: $1596-5996$ (print); 1596-9827 (electronic)

(C) Pharmacotherapy Group, Faculty of Pharmacy, University of Benin, Benin City, 300001 Nigeria.

Available online at http://www.tjpr.org

Original Research Article

http://dx.doi.org/10.4314/tjpr.v17i2.14

\title{
Baicalein administration protects against pentylenetetrazole-induced chronic epilepsy in rats
}

\author{
Peiyu Li, Xiuping Wang, Junwu Zhang* \\ Department of Neurology, The Affiliated First Hospital Of Jiamusi University, Jiamusi, Heilongjiang, 154000, China \\ *For correspondence: Email: JulianneVselen@yahoo.com; Tel/Fax: 0086-0454-8623330
}

Sent for review: 30 October 2017

Revised accepted: 23 January 2018

\begin{abstract}
Purpose: To investigate the protective effect of baicalein against chronic seizures in pentylenetetrazole induced epilepsy in a rat model.

Methods: A rat model of chronic epilepsy was prepared by administration of pentylenetetrazole at a dose of $35 \mathrm{mg} / \mathrm{kg}$ to Sprague-Dawley rats. The animals were divided into 6 groups (5 rats/group): normal control, model (untreated epilepsy) and four treatment groups that received separately, intraperitoneal injection of 20,30, 40 and $50 \mathrm{mg} / \mathrm{kg}$ baicalein, respectively, on alternate days for 30 days. On each day following baicalein treatment, behavioural alterations in the rats were assessed.

Results: Analyses of behavioural changes revealed significant $(p<0.05)$ decrease in pentylenetetrazole-induced convulsions by baicalein treatment at a dose of $50 \mathrm{mg} / \mathrm{kg}$. Immunohistochemical studies revealed that treatment with baicalein caused significant $(p<0.05)$ dosedependent reductions in the levels of inducible nitric oxide synthase (iNOS). Baicalein treatment inhibited alterations in cell morphology, and also inhibited pentylenetetrazole-induced increase in the proportion of glial fibrillary acidic protein (GFAP)-positive cells in a dose-dependent manner $(p<0.05)$. Real-time polymerase chain reaction (RT-PCR) analysis showed that baicalein significantly inhibited the expression of mRNA of NR1 subunit $N$ methyl $D$ aspartic acid (NMDA) receptor, without any effect on the expression of the NR2b ( $N$-methyl $D$-aspartate receptor subtype 2B) subunit mRNA $(p<0.05)$.

Conclusion: These results indicate that baicalein inhibits pentylenetetrazole-induced chronic seizures in rats via reduction in astrocytes, inhibition of neuronal death and reduction of NR1 mRNA expression. Thus, baicalein has a potential for development into a new drug for the treatment of chronic epilepsy.
\end{abstract}

Keywords: Pentylenetetrazole, Epilepsy, Baicalein, Convulsion, Inhibition, behavioural changes, Hippocampus

\begin{abstract}
This is an Open Access article that uses a funding model which does not charge readers or their institutions for access and distributed under the terms of the Creative Commons Attribution License (http://creativecommons.org/licenses/by/4.0) and the Budapest Open Access Initiative (http://www.budapestopenaccessinitiative.org/read), which permit unrestricted use, distribution, and reproduction in any medium, provided the original work is properly credited.

Tropical Journal of Pharmaceutical Research is indexed by Science Citation Index (SciSearch), Scopus, International Pharmaceutical Abstract, Chemical Abstracts, Embase, Index Copernicus, EBSCO, African Index Medicus, JournalSeek, Journal Citation Reports/Science Edition, Directory of Open Access Journals (DOAJ), African Journal Online, Bioline International, Open-J-Gate and Pharmacy Abstracts
\end{abstract}

\section{INTRODUCTION}

The flavone, 5, 6, 7-trihydroxyflavone, known as baicalein (Figure 1), is a natural isolate obtained from Scutellaria baicalensis Georgi. Baicalein has for long been an important component of traditional Chinese medicine [1]. It is used for treating ischemia and inflammatory diseases [1]. In vascular smooth muscle cells, baicalein attenuates endothelium intimal hyperplasia through inhibition of various pathways involved in inflammatory signalling, such as extracellular 
signal-regulated kinase (ERK), serine threonine kinase (Akt) and nuclear factor-kB (NF-KB) [2]. In the mouse model of radiation-induced inflammation, baicalein treatment inhibited inflammation by targeting the Forkhead family of transcription factors and NF-KB [3]. Baicalein also exhibits anticancer properties, and has been shown to inhibit colorectal cancer [4]. In prostate carcinoma cells, studies have shown that baicalein suppressed the rate of cell proliferation, and inhibited metastatic and migration potential [5]. Thus baicalein possesses promising antiinflammatory properties.

The death of neurons due to chronic seizures increases the susceptibility of the hippocampal tissues to further degradation, resulting in the development of chronic epilepsy [6]. Studies have revealed that administration of pentylenetetrazole leads to loss of neurons, resulting in chronic seizures [7]. The inflammatory factor, nitric oxide synthase is one of the prominent agents for induction of seizures $[8,9]$. In the present study, the protective effect of baicalein against pentylenetetrazole-induced chronic epilepsy in the rat was investigated.<smiles>O=c1cc(-c2ccccc2)oc2cc(O)c(O)c(O)c12</smiles>

Figure 1: Structure of baicalein $(5,6, \quad 7-$ trihydroxyflavone)

\section{EXPERIMENTAL}

\section{Animals and treatment protocol}

Thirty Sprague-Dawley rats (weighing 180 - 200 g) were obtained from the Shanghai Laboratory Animal Centre (SLAC, Shanghai, China). The animals were assigned randomly to 6 groups (5 rats/group): normal control, model and four treatment groups which were separately and intraperitoneally injected 20,30, 40 and $50 \mathrm{mg} / \mathrm{kg}$ baicalein. The animal model of chronic epilepsy was prepared by intraperitoneal administration of $35 \mathrm{mg} / \mathrm{kg}$ pentylenetetrazole for 28 consecutive days. Baicalein was injected on alternate days for 30 days. This study was performed in line with the guidelines contained in the Guide for the Care and Use of Laboratory Animals of the National Institute of Health [10]. All the experimental procedures were approved by the Institutional Animal Care and Use Committee (IACUC) of the First Affiliated Hospital of
Zhengzhou University, Zhengzhou, China (approval no. 109/ZUC).

\section{Analysis of alterations in rat behaviour}

Changes in the behaviour of the experimental rats were analysed on the day following each treatment with baicalein, for the 30 days of the study. A known five-point scale was used for the assessment of the stage of chronic seizure [8]. In this scale, no response, twitching of ear and face, body convulsion, jerking, side turn and seizure were assigned stages 1, 2, 3, 4 and 5, respectively.

\section{Extraction of hippocampus}

On day 31 , the animals were sacrificed, and whole brains were excised. The brain material was divided into two halves. The right half was subjected to paraffin embedment, followed by thin sectioning. Half of the brain material from each animal was subjected to RT-PCR analysis.

RNA extraction and reverse transcriptionpolymerase chain reaction (RT-PCR)

The total RNA from the hippocampus tissue was extracted using TRIzol reagent (Invitrogen Co., Carlsbad, CA). The extracted RNA was digested for 20 min using RNase-free DNase (Boehringer Mannheim, Indianapolis, IN) at $37^{\circ} \mathrm{C}$. The RNA

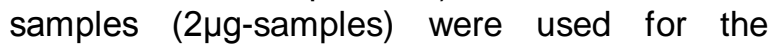
synthesis of cDNA by incubation for $1 \mathrm{~h}$ at $37{ }^{\circ} \mathrm{C}$ with Avian Myeloblastosis Virus (AMV) reverse transcriptase (Amersham Corp., Arlington Heights, IL). Sequence amplification to desired primers was performed using polymerase chain reaction (PCR). For the purpose of amplification, Mastercycler (Eppendorf, Hamburg, Germany) was used. The cycling consisted of denaturation for $4 \mathrm{~min}$ at $94{ }^{\circ} \mathrm{C}$, followed by 30 cycles of 30 sec at $94{ }^{\circ} \mathrm{C}, 30 \mathrm{sec}$ at $58{ }^{\circ} \mathrm{C}, 40 \mathrm{sec}$ at $72{ }^{\circ} \mathrm{C}$ and then $10 \mathrm{~min}$ at $72{ }^{\circ} \mathrm{C}$. After amplification, the samples were put in $1.5 \%$ agarose gels followed by visualization using ethidium bromide.

\section{Histopathological examination}

The paraffin-embedded hippocampal tissue sections were de-paraffinized in boiling xylene. The sections were then stained with haematoxylin and eosin $\mathrm{H}$ \& E). The stained sections were examined under light microscope (BX51M; Olympus, Tokyo, Japan; at a magnification of $x$ 10) for changes in tissue morphology. 


\section{Immuno-histological examination}

The paraffin-embedded hippocampus tissue sections were subjected to de-paraffinization in boiling xylene, followed by re-hydration in ethyl alcohol gradient. The sections were then treated with hydrogen peroxidase for blocking the activity of endogenous peroxidase enzyme. The tissue sections were then analysed for the expression of the activity of iNOS using rabbit anti-mouse primary antibodies (Santa Cruz Biotechnology, Inc.). The sections were examined and imaged using a Leica microscope equipped with a digital camera (Leica, Solms, Germany).

\section{Statistical analysis}

Statistical analysis was performed using SPSS 18.0 statistical software (SPSS, Inc., Chicago, IL, USA). Data are expressed as mean \pm standard error of the mean (SEM). Comparisons among multiple groups were performed using a one-way analysis of variance (ANOVA), and a least significant difference post hoc test. Values of $p<$ 0.05 were considered statistically significant.

\section{RESULTS}

\section{Effect of baicalein on chronic seizures induced by pentylenetetrazole in rats}

A known five? point scale [11] was used for the analysis of the effect of baicalein on convulsions caused by pentylenetetrazole in the rats. The seizure grades in the group treated with 50 $\mathrm{mg} / \mathrm{kg}$ baicalein were significantly lower than those in the model control group ( $p<0.02$; Figure 2). Although reduction in seizure grades was observed with baicalein at a dose of 30 $\mathrm{mg} / \mathrm{kg}$, the effect was maximum at the dose of 50 $\mathrm{mg} / \mathrm{kg}$.

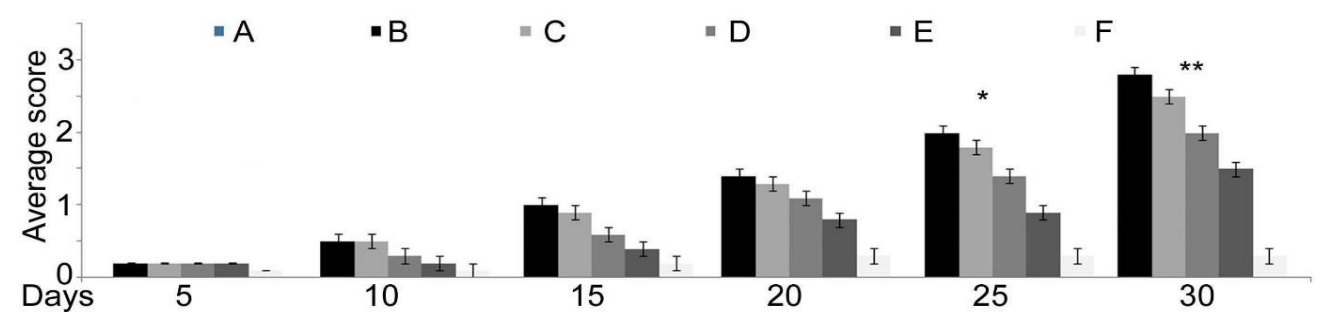

Figure 2: Inhibitory effect of baicalein on pentylenetetrazole-induced convulsions in rats. ${ }^{*} p<0.05$ and ${ }^{* *} p<0.02$ (untreated vs. 30 and $50 \mathrm{mg} / \mathrm{kg}$ groups, respectively). A, B, C, D, E and F stand for normal, model, $20 \mathrm{mg} / \mathrm{kg}, 30$ $\mathrm{mg} / \mathrm{kg}$ and $50 \mathrm{mg} / \mathrm{kg}$ treatment groups, respectively

\section{Effect of baicalein on iNOS in pentylenetetrazole-treated rats}

There was a significant increase in iNOS level in the pentylenetetrazole-treated group, when compared to the normal control group $(p<0.05)$. However, baicalein treatment for 30 days led to significant and dose-dependent reductions in iNOS $(p<0.05, p<0.02)$, with maximum reduction at a baicalein dose of $50 \mathrm{mg} / \mathrm{kg}$ (Figure 3).

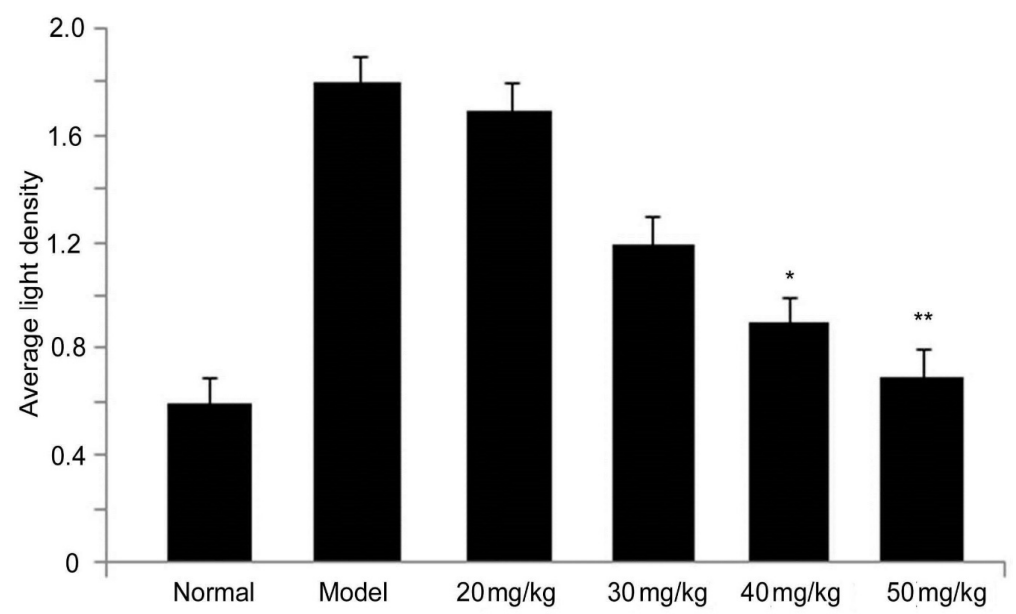

Figure 3: Effect of baicalein treatment on the expression of iNOS in pentylenetetrazole-treated rats. The rats were treated with $20,30,40$ and $50 \mathrm{mg} / \mathrm{kg}$ of baicalein on alternate days for 30 days. ${ }^{*} p<0.05$ and ${ }^{* *} p<0.02$ baicalein groups vs. model group 


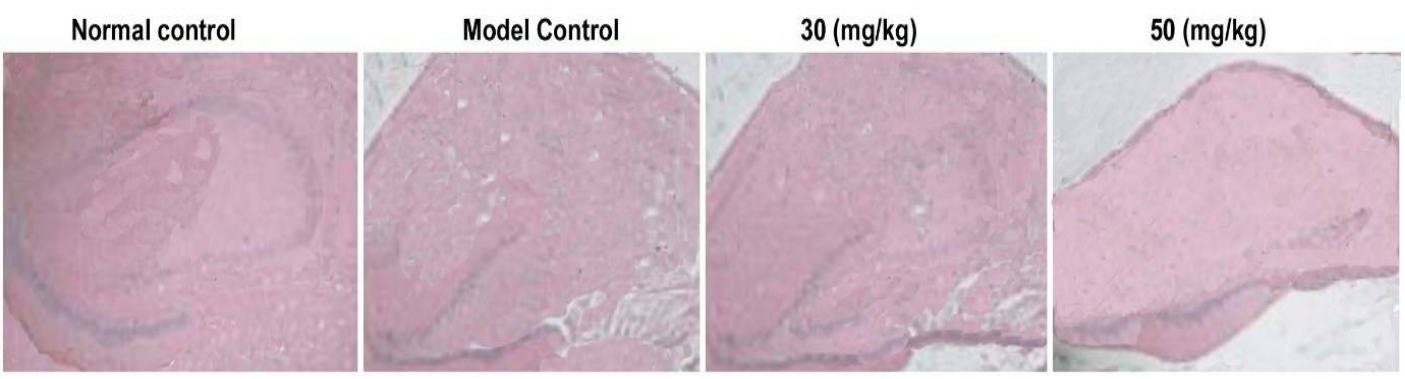

Figure 4: Effect of $30 \mathrm{mg} / \mathrm{kg}$ and $50 \mathrm{mg} / \mathrm{kg}$ doses of baicalein on hippocampal neuronal injury in pentylenetetrazole-treated rats. (H \& E stain, x 250)

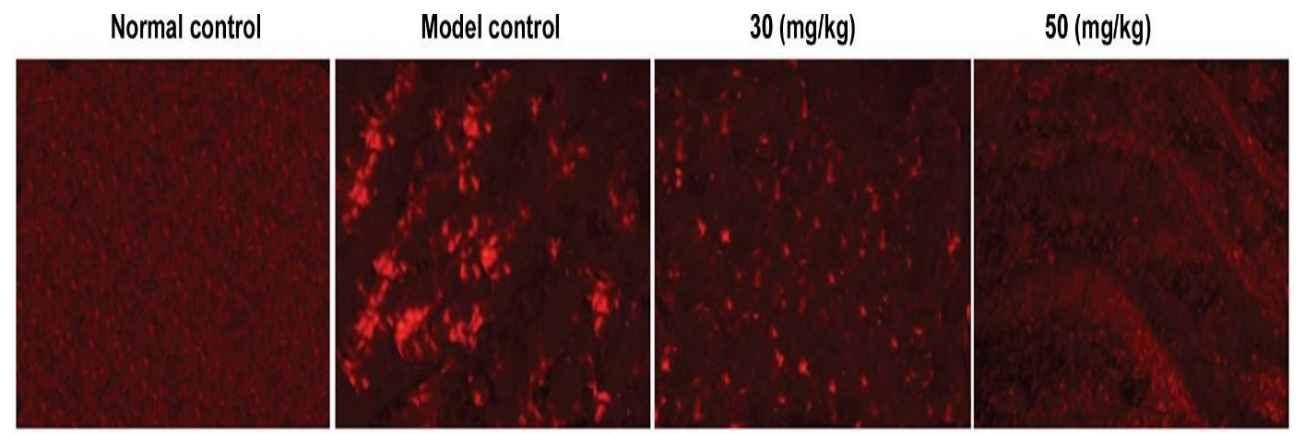

Figure 5: Effect of baicalein treatment on the population of GFAP-positive cells in rat hippocampus. Baicalein significantly reduced pentylenetetrazole-induced increases in hippocampal population of GFAP-positive cells. (x100)

\section{Effect of baicalein on pentylenetetrazole- induced cell injury in rats}

Microscopic examination of the rat hippocampal tissues revealed presence of wide intercellular spaces, irregular cellular morphology and apoptotic cells in the pentylenetetrazole (model) group. However, baicalein treatment inhibited the alterations in cell morphology in a dosedependent manner (Figure 4). The morphologies of the hippocampus tissues of the rats in the normal control group were similar to those in the $50 \mathrm{mg} / \mathrm{kg}$ baicalein treatment group.

\section{Effect of baicalein on astrocytic hyperplasia}

Pentylenetetrazole significantly increased the proportion of GFAP-positive cells in the rat hippocampus, when compared to the control group. However, treatment of the rats with baicalein dose-dependently inhibited the pentylenetetrazole-induced increases in the proportion of GFAP-positive cells $((p<0.05$; Figure 5). The proportion of GFAP-positive cells in the normal control and in the $50 \mathrm{mg} / \mathrm{kg}$ baicalein treatment groups were similar.

\section{Effect of baicalein on NMDA receptor level}

Results from RT-PCR analysis revealed a significant increase in the expression of NR1 mRNA in the pentylenetetrazole group, when compared to the normal control group $(p<0.05)$. However, treatment of the rats with baicalein significantly inhibited the expression of NR1 mRNA (Figure 6). Analysis of the NR2b mRNA level showed no changes in the pentylenetetrazole group relative to the normal control group (Figure 6).

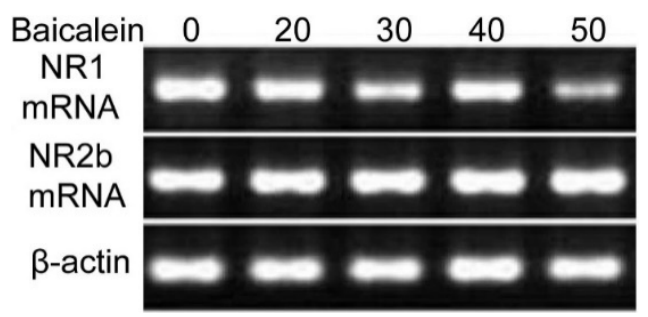

Figure 6: Effect of baicalein on expression of NR1 mRNA in the pentylenetetrazole-treated rats. RT-PCR analysis showed a significant reduction in the expression of NR1 mRNA in baicalein-treated rats, when compared to the model group

\section{DISCUSSION}

In the present study, the protective effect of baicalein on chronic seizures induced in rats by administration of pentylenetetrazole was investigated. The results revealed that baicalein treatment inhibited increases in proportion of astrocytes, and also inhibited neuronal loss and expression of NR1 mRNA in the rat hippocampus. It has been reported that the 
development of chronic seizures as a result of neurological disorders in the rat model can be inhibited by administration of chemotherapeutic agents $[8,12]$.

The results from the present study demonstrate that baicalein inhibited pentylenetetrazoleinduced convulsions in the rat model at comparatively low doses. This is important, because existing anti-convulsive agents exhibit their effects at much higher doses [12]. Furthermore, in the rat model of pentylenetetrazole-induced chronic epilepsy, baicalein treatment markedly reduced seizure grades. These findings suggest that baicalein is an efficient anti-convulsive agent, relative to already-established anti-convulsive compounds. Studies in animal models have shown that the development and progression of chronic seizures is associated with the expression of iNOS $[8,9]$.

The expression of iNOS is higher in the tissues of animals with chronic epilepsy [9]. In the present study pentylenetetrazole administration to rats increased the expression of iNOS. This is consistent with earlier reports. However, treatment of the rats with baicalein inhibited pentylenetetrazole-induced up-regulation of iNOS expression. These results suggest that baicalein inhibited development of chronic seizures in the rats through suppression of iNOS expression.

During chronic seizures, neuronal death enhances the susceptibility of the hippocampal tissues to further degradation, leading to the development of chronic epilepsy [9]. Pentylenetetrazole administration to rats triggers neuronal death and leads to development of chronic seizures [13]. Results from the present study showed presence of large intercellular spaces and deranged cellular morphology in the rat hippocampal tissues after pentylenetetrazole administration. However, baicalein treatment reversed these changes in cellular morphology induced by pentylenetetrazole.

Astrocytes are responsible for increasing the expression of cytokines which in turn initiate inflammatory processes in neuronal cells [14]. The population of astrocytes in the hippocampus of pentylenetetrazole-treated rats has been reported to be elevated, indicating the onset of epilepsy [15]. In the present study, pentylenetetrazole increased the proportion of GFAP-positive cells in rat hippocampus. However, the pentylenetetrazole-induced increase in the proportion of GFAP-positive cells was annulled by baicalein.

\section{CONCLUSION}

The results obtained in this study strongly suggest that baicalein treatment is effective in the prevention of chronic seizures caused by administration of pentylenetetrazole in rats. It exerts this effect through reduction in astrocytes, inhibition of neuronal death and reduction of NR1 mRNA expression. Thus, baicalein has a potential for use in the treatment of chronic epilepsy but this requires further investigations.

\section{DECLARATIONS}

\section{Conflict of Interest}

The authors declare that they have no competing interests with regard to this work.

\section{Author contributions}

We declare that this work was done by the authors named in this article, and all liabilities pertaining to claims relating to the content of this article will be borne by the authors. Peiyu Li and Xiuping Wang performed the experimental work and compiled the results. Junwu Zhang designed the study and wrote the manuscript. The manuscript was read thoroughly and approved by all the authors.

\section{REFERENCES}

1. Li-Weber M. New therapeutic aspects of flavones: the anticancer properties of Scutellaria and its main active constituents Wogonin, Baicalein and Baicalin. Cancer Treat Rev 2009; 35: 57-68.

2. Peng CY, Pan SL, Huang YW, Guh JH, Chang YL, Teng CM. Baicalein attenuates intimal hyperplasia after rat carotid balloon injury through arresting cell-cycle progression and inhibiting ERK, Akt, and NF-kappaB activity in vascular smooth-muscle cells. Naunyn Schmiedebergs Arch Pharmacol 2008; 378: 579-588.

3. Lee EK, Kim JM, Choi J, Jung KJ, Kim DH, Chung SW, Ha YM, Yu BP, Chung HY. Modulation of NF-kappaB and FOXOs by baicalein attenuates the radiationinduced inflammatory process in mouse kidney. Free Radic Res 2011; 45: 507-517.

4. Lea MA, Ibeh C, Deutsch JK, Hamid I, DesBordes C. Inhibition of growth and induction of alkaline phosphatase in colon cancer cells by flavonols and flavonol glycosides. Anticancer Res 2010; 30: 36293635.

5. Pidgeon GP, Kandouz M, Meram A, Honn KV. Mechanisms controlling cell cycle arrest and induction of apoptosis after 12-lipoxygenase inhibition in prostate cancer cells. Cancer Res 2002; 62: 2721-2727. 
6. Bengzon J, Kokaia Z, Elmér E, Nanobashvili A, Kokaia $M$, Lindvall $O$. Apoptosis and proliferation of dentate gyrus neurons after single and intermittent limbic seizures. Proc Natl Acad Sci USA 1997; 94: 1043210437.

7. Oses JP, Leke R, Portela LV, Lara DR, Schmidt AP, Casali EA, Wofchuk S, Souza DO, Sarkis JJ. Biochemical brain markers and purinergic parameters in rat CSF after seizure induced by pentylenetetrazol. Brain Res Bull 2004; 64: 237-242.

8. Demehri S, Homayoun H, Honar H, Riazi K, Vafaie $K$, Roushanzamir F, Dehpour AR. Agmatine exerts anticonvulsant effect in mice: modulation by $\alpha 2$ aadrenoceptors and nitric oxide. Neuropharmacology 2003; 45: 534-542.

9. Bahremand A, Ziai P, Khodadad TK, Payandemehr B, Rahimian $R$, Ghasemi $A$, Ghasemi $M$, Hedayat $T$, Dehpour AR. Agmatine enhances the anticonvulsant effect of lithium chloride on pentylenetetrazole-induced seizures in mice: Involvement of L-arginine/nitricoxide pathway. Epilepsy Behav 2010; 18: 186-192.

10. Wang $Y H$, Yin $L T$, Anghui $Y, L i \quad X L, W u$ KG. Hypoglycemic and anti-depressant effects of Zuogui
Jiangtang Jieyu formulation in a model of unpredictable chronic mild stress in rats with diabetes mellitus. Expt Ther Med 8: 281-285: 2014

11. Fathollahi $Y$, Motamedi $F$, Semnanian S, Zardoshti $M$. Examination of persistent effects of repeated administration of pentylenetetrazol on rat hippocampal CA1: evidence from in vitro study on hippocampal slices. Brain Res 1997; 758: 92-98.

12. Su RB, Wei $X L$, Zheng JQ, Liu Y, Lu XQ, Li J. Anticonvulsive effect of agmatine in mice. Pharmacol Biochem Behav 2004; 77: 345-349.

13. Obay BD, Taşdemir E, Tümer C, Bilgin H, Atmaca $M$. Dose dependent effects of ghrelin on pentylenetetrazole-induced oxidative stress in a rat seizure model. Peptides 2008; 29: 448-455.

14. Ravizza T, Gagliardi B, Noé F, Boer K, Aronica $E$, Vezzani $A$. Innate and adaptive immunity during epileptogenesis and spontaneous seizures: evidence from experimental models and human temporal lobe epilepsy. Neurobiol Dis 2008; 29: 142-160.

15. Stringer JL. Repeated seizures increase GFAP and vimentin in the hippocampus. Brain Res 1996; 717: 147153. 